\title{
O PAPEL DO FUTEBOL EM CONTEXTOS PÓS-CONFLITO: O CASO DOS BALCÃS
}

\author{
Pedro Sousa Almeida, Universidade de Coimbra - UC, Coimbra - Portugal
}

\begin{abstract}
RESUMO
Partindo da ideia que o futebol constitui um campo privilegiado de acesso ao estudo da realidade social, este artigo explora o seu papel no fortalecimento de sentimentos ultra nacionalistas e xenófobos na guerra da ex-Jugoslávia. Aborda-se criticamente o actual estado do debate teórico sobre futebol e nacionalismo, analisando a sua relação com a política e conflito no contexto dos Balcãs. Através da análise da utilização do futebol como instrumento de paz e integração de diferentes grupos étnicos em contextos pósconflito, procura-se mostrar que a eficácia desta abordagem se resume ao futebol amador, pelo que a sua aplicabilidade ao nível das competições profissionais de futebol, especialmente na região dos Balcãs, se torna bastante questionável.
\end{abstract}

Palavras-Chave: Futebol; Nacionalismo; Balcãs; Conflito; Reconciliação.

\section{THE ROLE OF FOOTBALL IN POST-CONFLICT CONTEXTS: THE BALKANS}

\begin{abstract}
From the idea that football is a uniquely favourable field for studying social reality, this paper explores its role in reinforcing ultra-nationalist and xenophobic feelings during the war in the former Jugoslavia. The current state of debate about football and nationalism will be approached, analysing its link between politics and the conflict in the Balcans. By analysing the utilisation of football as an instrument of peace and integration of different ethnicities in post-conflict contexts, our purpose is to show that the efficacy of this approach is limited to amateur football, which means that its applicability to professional competitions, especially in the Balcans, is highly questionable.
\end{abstract}

Key-Words: Football; Nationalism; Balkans; Conflict; Reconciliation. 


\section{INTRODUÇÃO}

Este artigo analisa a forma como o futebol serviu como veículo de intensificação de sentimentos nacionalistas no conflito dos Balcãs. Procura-se, assim, contribuir para o debate teórico que, de um modo geral, tem ignorado o papel que o futebol desempenhou no desmembramento da ex-Jugoslávia. ${ }^{1}$ Para além disso, discute-se a possibilidade do futebol, na actualidade, não constituir necessariamente um elemento de exclusão do ‘outro', abrindo, pelo contrário, novas possibilidades de diálogo e de comunicação entre diferentes grupos étnicos. ${ }^{2-3}$

A discussão teórica em torno do fenómeno do futebol que se iniciou nos finais da década de 1960 na Grã-Bretanha tem-se centrado quase exclusivamente em questões de identidade e violência. Primeiramente focados no contexto britânico, os estudos têm-se vindo a alargar a outras áreas geográficas e culturais. Apesar da diversidade de perspectivas teóricas, grande parte dos investigadores não tem evidenciado uma preocupação em relacionar as manifestações violentas que ocorrem nos estádios de futebol com o contexto político mais abrangente no qual elas se inserem. Uma das razões terá certamente a ver com o facto da generalidade das pesquisas académicas se centrar em contextos democráticos relativamente consolidados. Assim, a tendência geral é em considerar, não sem alguma simplificação, que os episódios de violência, xenofobia e racismo que ocorrem nos estádios de futebol circunscrevem-se apenas a contextos específicos e têm apenas como protagonistas grupos organizados de adeptos. ${ }^{4-6}$

$\mathrm{O}$ artigo está estruturado em três partes. Na primeira parte, pretende-se abordar o debate teórico sobre futebol e nacionalismo. Apesar de os estudos sobre o nacionalismo no futebol não constituírem ainda um corpo teórico suficientemente consistente sob o ponto de vista crítico, procura analisar-se o estado actual do debate académico na área. $\mathrm{Na}$ segunda parte, destaca-se o papel que o futebol desempenhou no conflito da ex-Jugoslávia, evidenciando a sua capacidade de agregação e intensificação de sentimentos nacionalistas. No terceiro ponto, discutem-se as potencialidades e limitações do futebol na integração e/ou na exclusão de diferentes comunidades étnicas no contexto dos Balcãs. Nas considerações finais, sintetizam-se as conclusões que se foram tirando ao longo do texto e apontam-se algumas pistas para uma agenda de investigação futura sobre o papel do futebol em contextos pós-conflito.

Conexões: revista da Faculdade de Educação Física da UNICAMP, Campinas, v. 10, n. 3, p. 1-19, set./dez. 2012. ISSN: 1983-9030 


\section{FUTEBOL E NACIONALISMO}

De uma forma geral, desde a publicação dos primeiros trabalhos até à actualidade, o nacionalismo no contex to do futebol tem sido atribuído aos ultras $^{1}$ e aos hooligans $^{2}{ }^{7,8,9}$

De facto, face ao crescimento e consequente visibilidade mediática que estes grupos organizados foram conquistando, as manifestações nacionalistas no futebol foram marcando uma presença assídua nos estádios europeus. Neste sentido, a maioria dos investigadores tem enfatizado a necessidade de realçar as atitudes e os cânticos xenófobos que constituem parte do reportório desses grupos, como forma de os diferenciar do chamado 'adepto tradicional'. Nas palavras de Lowles: ${ }^{10: 117-118}$

A maior parte dos hooligans ingleses adopta um nacionalismo agressivo quando está a viajar pelo estrangeiro. Eles glorificam tudo o que é inglês e ridicularizam tudo o que é diferente nos outros países e nos outros grupos étnicos. O racismo inglês torna-se ele mesmo.

Na mesma linha de raciocínio, Roversi e Balestri ${ }^{11}$ chamam a atenção para a crescente politização das claques italianas que têm desvirtuado a autenticidade do 'espírito ultra', inicialmente apolítico e focado em formas específicas de apoio aos clubes. Devido a uma série de acontecimentos, dos quais se destaca a morte de um adepto em 1995 na sequência de confrontos entre grupos rivais e a crescente repressão e violência policial, entre outros aspectos, os grupos ultra tornaram-se mais violentos, 'preparando um terreno fértil para atitudes racistas e xenófobas' ${ }^{11:} 138$ Efectivamente, sensivelmente a partir da segunda metade da década de 1990, a politização destes grupos tem vindo a ocupar um lugar de destaque no debate académico. Assim se explica que a maioria dos autores tem defendido

\footnotetext{
${ }^{1}$ Os ultras constituem uma subcultura de adeptos, que teve origem em Itália, na década de 1970 e que se encontra, hoje, fortemente presente em vários países europeus com maior representação na Europa do Sul. Estes adeptos procuram, através de um conjunto complexo de atitudes, valores e normas, diferenciar-se tanto dos adeptos 'tradicionais' como dos hooligans britânicos. Apesar algumas das acções e posturas que caracterizam estes grupos se assemelharem às dos hooligans, é redutor considerar os ultras como os seus equivalentes.

${ }^{2}$ Os hooligans constituem uma subcultura de adeptos, originária na Grã-Bretanha em finais de década de 1960 e que se caracteriza essencialmente pela procura de confrontação física ou simbólica com outros grupos rivais e/ ou com as forças policiais. Devido à crescente vigilância por parte das autoridades policiais em alguns dos países com mais incidentes protagonizados por estes grupos, os hooligans adoptaram, a partir dos finais de década de 1980, o chamado estilo casual que se caracteriza pelo uso de vestuário de estilistas de renome (Fred Perry, Burberrys, por exemplo) também como forma de afirmação perante outros grupos rivais.
}

Conexões: revista da Faculdade de Educação Física da UNICAMP, Campinas, v. 10, n. 3, p. 1-19, set./dez. 2012 3 ISSN: 1983-9030 
a existência, no seio dos ultras, de elementos ligados à extrema-direita, não só em Itália como também em Espanha. ${ }^{5}$

Em Portugal, não obstante a presença de algum tipo de retórica nacionalista e xenófoba em certos grupos, a influência de ideologias fascistas tem sido relativamente ténue. ${ }^{12}$ (O enfoque dos investigadores portugueses tem-se centrado, essencialmente, nos ultras que compõem as torcidas organizadas, salientando as suas especificidades e particularidades face ao restante contexto europeu. ${ }^{12-13}$ Além do forte envolvimento emocional que os une ao seu clube, os ultras têm transportado para os estádios alguns dos valores característicos das sociedades mediterrânicas, tais como as noções tradicionais de honra, vergonha e masculinidade. Incorporando uma linguagem bélica e uma postura agressiva, estes grupos caracterizam-se por uma predisposição para os comportamentos hostis e violentos. Para além destes aspectos, tem sido salientada a "presença de membros de extrema-direita, associada a comportamentos de nacionalismo exacerbado, xenofobia e racismo". 13:3

No entanto, não se pretende, neste artigo, aprofundar o debate sobre a presença mais ou menos notória de ideologias nacionalistas junto dos grupos organizados de adeptos. O que se procura salientar, neste ponto, é que de uma forma ou de outra, grande parte dos trabalhos académicos acaba por cair num certo reducionismo, sob duas formas distintas. Por um lado transmitem a ideia de que a xenofobia, o nacionalismo e o racismo são fenómenos praticamente exclusivos de grupos específicos de adeptos, quando na realidade este tipo de ideologias é algo que também está presente junto dos aficionados 'tradicionais'. Por outro lado, os investigadores não têm prestado a devida atenção à forma como os processos coloniais, o racismo e o eurocentrismo tiveram um papel decisivo na construção e consolidação da identidade europeia. ${ }^{14-15}$ Deste modo, pode afirmar-se que o nacionalismo não constitui um campo verdadeiramente autónomo nos estudos sobre futebol e sociedade, sendo antes problematizado como uma ramificação das investigações sobre determinadas subculturas de adeptos.

Não obstante, apesar de ocupar um espaço muito menor na literatura especializada, a relação entre futebol e nacionalismo também tem sido explorada sob outras perspectivas. O caso do Athletic de Bilbao é paradigmático. Fundado em 1898, o Atlhletic adoptou, desde 1919, uma política de contratações que o torna num caso peculiar, especialmente no Conexões: revista da Faculdade de Educação Física da UNICAMP, Campinas, v. 10, n. 3, p. 1-19, set./dez. 2012. 4 ISSN: $1983-9030$ 
contexto global actual. A filosofia do clube consiste, sinteticamente, em contratar apenas jogadores de origem basca. ${ }^{16}$

Tendo em conta o percurso histórico do Athletic e o contexto político e cultural no qual o clube se inscreve, torna-se evidente que a especificidade que o caracteriza se encontra, em parte, altamente veiculada à afirmação da identidade basca. Efectivamente, devido a uma série de razões, que vão desde a obrigação de mudança de nome durante os anos da ditadura franquista (passando a designar-se por Atlético de Bilbao) até à proibição do uso da língua basca, o clube foi consolidando a sua posição enquanto arena privilegiada de contestação ao fascismo, tornando-se num dos ícones da identidade basca. Neste sentido, não foi pois de estranhar que, durante o período de transição democrática o Athletic se tenha envolvido politicamente na defesa da autonomia e do nacionalismo basco. É interessante verificar que a retórica nacionalista ainda se observa actualmente através, por exemplo, dos cânticos entoados pelos adeptos no estádio onde actua a equipa.

Apesar dos exemplos atrás referidos, as relações que se estabelecem entre futebol, nacionalismo e o Estado têm sido pouco exploradas no debate teórico. Em Football, Nationality and the State, Duke e Crolley ${ }^{17}$ aprofundam o modo como o futebol representou, em determinados contextos, tais como na ex-União Soviética, uma extensão da própria estrutura do estado. Mais do que um aproveitamento político dos êxitos desportivos de determinadas equipas ou da selecção nacional, argumenta-se que o "futebol era, simultaneamente, parte e reflexo do estado socialista". ${ }^{17: 85}$ Assim, contrariamente ao que sucedeu, por exemplo, em Portugal durante o regime salazarista ${ }^{3}$, o grau de interferência dos estados socialistas no desporto, em geral, e no futebol, em particular, era altíssimo: "a importância política do desporto residia no seu potencial para demonstrar a superioridade do comunismo sobre o capitalismo, através da conquista de um maior número de troféus". 17: 88

\footnotetext{
${ }^{3}$ Contrariando a ideia comummente aceite do Portugal dos 'três efes' -futebol Fátima e fado- Serrado (2009) defende a tese que o governo salazarista não tinha um plano para instrumentalizar o futebol em seu benefício. De acordo com o autor, o regime fascista apenas esporadicamente fez uso político das conquistas dos clubes e da selecção portuguesa. Aliás, o regime, posicionando-se veementemente contra a profissionalização e internacionalização do futebol, temia o comportamento das multidões, no sentido em que elas poderiam servir de base para uma contestação política organizada e ampliada.
} 
É interessante verificar os contornos dessa ligação. Numa tentativa de demarcação do espírito individualista característico das sociedades capitalistas, a ênfase colocava-se, essencialmente, no trabalho de equipa. Assim, a organização e o modelo socialista do desporto procurava enfatizar o papel histórico da classe operária, diferenciando-se da crescente profissionalização e comercialização que caracterizava o futebol europeu e outras modalidades nos países ocidentais. Essencialmente, o desporto era visto como parte da emancipação cultural das classes trabalhadoras, sendo que este tipo de modelo permaneceu intacto até finais de década de $1980 .{ }^{17: 92}$

Outro aspecto que merece ser destacado diz respeito ao apoio institucional estatal que era prestado a muitas equipas da Europa de Leste. Efectivamente, a ligação entre vários clubes e o Estado ia além do significado simbólico dos seus nomes ${ }^{4}$, já que muitos deles eram patrocinados pelo exército, ministério da segurança ou polícia secreta. Ao mesmo tempo que se intensificava o apoio a determinadas equipas, verificava-se um processo de marginalização de outros clubes, especialmente aqueles que se encontravam historicamente associados ao nacionalismo étnico. ${ }^{18}$ Assim, uma das difíceis tarefas dos regimes socialistas na Europa de Leste consistia em tentar conter ou reprimir qualquer tentativa de afirmação de identidades locais, regionais ou religiosas já que esse tipo de manifestações, tal como aliás se veio a verificar, contribuiu para o despoletar de sentimentos ultra nacionalistas, que se traduziram em aspirações separatistas.

\section{O PAPEL DO FUTEBOL NO CONFLITO DOS BALCÃS}

Em How football explains the world, Franklin Foer ${ }^{19}$ reforça a ideia que o futebol, sendo mais do que um simples jogo, permite um olhar particular para as sociedades contemporâneas. Recorrendo a diversos estudos de caso, o autor distingue vários tipos de nacionalismo. Tome-se como exemplo a Catalunha e a antiga Jugoslávia. De acordo com a sua leitura, estes casos diferenciam-se radicalmente, já que enquanto o nacionalismo catalão terá florescido como resultado do nacionalismo liberal, o nacionalismo sérvio

\footnotetext{
${ }^{4}$ Como facilmente se comprova através dos nomes dos principais clubes, tais como o 'Estrela Vermelha' (Crvena Zvezda) ou o 'Partizan de Belgrado' (Fudbalski klub Partizan) as relações entre o poder político jugoslavo e o futebol eram significativas (MILLS, 2009).
} 
emergiu num registo "irracional" 19: ${ }^{193}$ Este tipo de abordagem parece bastante discutível. De facto, e apesar dos olhares ocidentais exteriores ao conflito serem, na sua maioria, notoriamente 'anti-Sérvios', seria altamente redutor abordar a desintegração da exJugoslávia sob uma perspectiva tão normativa e enviesada. Assim, a compreensão dos diversos contornos do conflito exige, naturalmente, uma análise mais cuidada e aprofundada.

Um dos momentos históricos mais marcantes na antiga Jugoslávia foi a morte de Josip Tito, líder histórico dos partizans e mais tarde presidente do país. Anunciada durante um jogo entre o Hadjuk Split e o Estrela Vermelha, o seu falecimento desencadeou, no estádio, uma manifestação de enorme pesar que se fez notar, primeiramente, pelo silêncio e, em seguida, por cânticos de sentida homenagem. ${ }^{1}$

Contrariando a ideia comummente aceite acerca da fragilidade do patriotismo jugoslavo, esta manifestação espontânea sugere que o grau de identificação para com o projecto de uma Jugoslávia unida tinha, de facto, alguma consistência:

Sob o regime de Tito, a Jugoslávia conseguiu adquirir maior unidade quando comparada com o que tinha acontecido no país a seguir à Primeira Guerra Mundial [...] A política da Jugoslávia de não alinhamento com a União Soviética e a constante ameaça de uma invasão soviética, juntamente com a percepção da ameaça do imperialismo ocidental, ajudaram a fortalecer a unificação das várias repúblicas jugoslavas. ${ }^{20: 309}$

Neste sentido, parece fazer algum sentido afirmar que a morte de Tito fez despoletar sentimentos ultra nacionalistas que estariam relegados para um plano secundário. Essa é, pelo menos, a abordagem dominante em vários trabalhos publicados. ${ }^{21}$

Dentro do contexto do desmembramento da Jugoslávia, será interessante explorar o papel que o futebol teve em todo o processo de separação do país. De facto, os acontecimentos sugerem claramente que o futebol foi mais do que um espelho da turbulência política e social. Ele próprio serviu de palco aglutinador dos diferentes nacionalismos. Neste ponto particular, é importante destacar duas características estruturais da Jugoslávia que, de uma forma ou de outra, terão sido responsáveis pela contenção do nacionalismo extremista. Em primeiro lugar, importa realçar que o sistema de partido único não abria espaço para a mobilização étnica. Por outro lado, a própria estrutura federal jugoslava foi construída em Conexões: revista da Faculdade de Educação Física da UNICAMP, Campinas, v. 10, n. 3, p. 1-19, set./dez. 2012. ISSN: 1983-9030 
torno de determinados grupos étnicos que mantinham o controlo e o poder sobre outras minorias. ${ }^{22}$ Deste modo, o futebol, sendo um jogo que enfatiza como nenhum outro as noções de oposição e rivalidade, terá efectivamente servido como palco de efervescência identitária. Dito por outras palavras, as características políticas da federação jugoslava, bem como a composição multiétnica do país, terão favorecido o surgimento de determinados espaços nos quais as várias identidades pudessem ser exibidas e celebradas. Neste sentido, o futebol terá desempenhado um papel significativo em todo o processo de desmembramento da Jugoslávia.

Tome-se como exemplo o jogo entre o Dínamo de Zagreb e o Estrela Vermelha realizado em Zagreb, em Maio de 1990, pouco tempo antes de eclodir o conflito. A partida, que veio a ser interrompida, ficou marcada por confrontos violentos em larga escala que envolveram milhares de adeptos croatas, sérvios e forças policiais durante todo o dia. Tendo-se iniciado nas ruas da cidade, os tumultos continuaram no estádio, o que obrigou que a equipa do Estrela Vermelha fosse retirada de helicóptero. Os enfrentamentos prolongaram-se durante a noite, especialmente entre os adeptos do Dínamo de Zagreb e a polícia. Para além dos elevadíssimos prejuízos materiais resultantes de pilhagens de automóveis e estabelecimentos comerciais, os números oficiais apontam para mais de cem feridos, alguns dos quais com gravidade, especialmente polícias e croatas. ${ }^{20}$

Ao mesmo tempo que ocorriam os confrontos entre adeptos, que estavam a ser transmitidos pela televisão, um outro episódio, envolvendo um conhecido jogador croata, marcou esse dia. Zvonimir Boban, capitão do Dínamo de Zagreb, convencido de que as forças policiais estavam a ter uma atitude desproporcionada para com os adeptos, protegendo os seguidores do Estrela Vermelha e agredindo os do Dínamo, atacou um polícia a pontapé. É importante referir que a percepção geral que os croatas partilhavam na altura apontava no sentido das forças policiais representarem o domínio sérvio sob as restantes etnias, especialmente a croata. ${ }^{1}$ Nesta perspectiva, esse acto não se tratou de uma simples reacção às acções policiais naquela altura, sendo antes percepcionado como um "desafio simbólico face à legitimidade de toda a federação jugoslava". 20: 312 O facto do Dínamo de Zagreb ter erguido um monumento de homenagem, no estádio do clube, a todos os 'Bad Blue Boys' (grupo organizado de adeptos) que morreram durante a guerra, é 
revelador do significado simbólico deste local, já que para muitos, foi neste lugar específico que a guerra verdadeiramente começou. ${ }^{18}$

Outro dos episódios que reforça a ideia acerca do papel activo que o futebol desempenhou em todo o processo de desmembramento do país deu-se aquando da final da, então, designada taça dos campeões europeus, disputada em Itália entre o Estrela Vermelha e o Olympic de Marselha, em Março de 1991. No início da segunda parte, os adeptos do Estrela Vermelha desfraldaram uma gigantesca bandeira da Sérvia com cerca de sessenta metros, cobrindo grande parte das bancadas. Numa altura em que a mediatização e comercialização do futebol já se fazia sentir, especialmente no espaço europeu, esta manifestação nacionalista não deixou de ter um impacto significativo na aglutinação da identidade sérvia, já que, apesar dos cerca de vinte mil adeptos sérvios presentes no estádio, registou-se uma notável ausência de bandeiras jugoslavas. ${ }^{1: 1198}$

Na realidade, o futebol não pode ser visto somente como um jogo, já que devido a um conjunto de razões, ele tornou-se central na representação das culturas populares. Para além da importância simbólica que lhe tem sido atribuída, o futebol também sido usado como um meio de adquirir reconhecimento. Foi o que aconteceu naquele que é hoje o território da Croácia. Numa altura em que a Croácia já se tinha auto-proclamado como uma nação independente, os seus líderes convidaram os Estados Unidos para a realização de um jogo de futebol. Como se pode concluir, não se tratava apenas de um simples jogo, já que ele serviu não só como veículo de agregação de sentimentos étnicos e identitários, mas também como tentativa de reconhecimento internacional:

Para os croatas, este jogo tinha um enorme significado político. A equipa norte-americana, representando a nação mais poderosa do mundo, estava a ajudar a Croácia a celebrar a sua independência da Jugoslávia e a cimentar o seu estatuto na comunidade mundial. ${ }^{20: 314}$

Em suma, as ligações entre futebol, política e conflito foram muito acentuadas na antiga Jugoslávia. Para além dos exemplos acima citados, o envolvimento directo e activo dos grupos organizados de adeptos dos clubes - sérvios e croatas - em organizações paramilitares, sustenta a ideia de que o futebol foi, efectivamente, um poderoso instrumento no revivalismo dos nacionalismos no contexto dos Balcãs. ${ }^{18} \mathrm{O}$ que é interessante verificar é que, embora tenha sido pouco explorado nos trabalhos académicos da área, o futebol continua a servir como unidade de análise privilegiada para explicar as Conexões: revista da Faculdade de Educação Física da UNICAMP, Campinas, v. 10, n. 3, p. 1-19, set./dez. 2012. ISSN: 1983-9030 
profundas mudanças ocorridas nos países que emergiram da dissolução da Jugoslávia. Reportando-se ao caso sérvio, Nielsen ${ }^{1}$ enfatiza, precisamente, a utilidade do futebol como factor explicativo para a transição do país rumo à consolidação democrática. A este propósito, é importante destacar que as mudanças políticas ocorridas a partir da década de 1980 parecem ter aberto caminho à violência (traduzindo-se em punições por parte das entidades internacionais reguladoras, tais como a UEFA), ao decréscimo acentuado do número de adeptos nos estádios, à corrupção e à impunidade de alguns dos fomentadores de um clima de violência e intimidação. ${ }^{1,18}$ Apesar da violência no futebol constituir, na realidade, um fenómeno mundial, os seus contornos têm assumido uma dimensão incomparavelmente maior nesta região, ainda que grande parte dos episódios de violência, corrupção e intimidação não tenham vindo a ter a respectiva cobertura mediática na Europa ocidental.

\section{O FUTEBOL COMO ELEMENTO DE EXCLUSÃO VERSUS INCLUSÃO}

Foi durante a década de 1980, na antiga Jugoslávia, que se começaram a sentir as reformas do regime político, assistindo-se a uma crescente competição pelo poder. A abordagem dominante em muitos dos trabalhos publicados sobre o conflito dos Balcãs sugere que a morte de Josip Tito foi o princípio do fim do regime socialista. ${ }^{21}$ Contrariando esta tese, Dov Ronen ${ }^{22}$ argumenta que a ausência de conflitos étnicos em larga escala desde a Segunda Guerra Mundial, só por si já seria suficiente para contestar as ideias acerca dos supostos antagonismos e ressentimentos étnicos que estariam escondidos desde essa altura. Para além do mais, salientam-se as falhas das teorias dominantes, realçando o facto do conflito, exceptuando o caso do Kosovo, não ter surgido antes de 1991, isto é, onze anos após o falecimento de Tito. ${ }^{22}$

Assim, o autor sugere que, ao contrário da percepção ocidental, a Jugoslávia não tinha propriamente um problema étnico. Essa questão só se colocou a partir do momento em que as diferentes etnias perceberam o tipo de alianças que se estavam a formar com os vários actores internacionais, nomeadamente com os países directamente envolvidos no conflito, tal como os Estados Unidos. Tomando como exemplo os sérvios que viviam em regiões nas quais a maioria da população era croata, Ronen argumenta que estes perceberam que, 
enquanto minorias em estados unitários, seriam reprimidos, tornando-se cidadãos de segunda [...]. Face a esta percepção de ameaça eles estavam prontos a resistir. O ponto central do nosso argumento é que os factores psicológicos (percepção de ameaça) são os principais responsáveis pela erupção do conflito e não diferenças étnicas ou religiosas, antipatia ou hostilidade de outros grupos, ou o fim do regime autoritário. $^{22: 103}$

Independentemente das principais origens da guerra dos Balcãs, tem-se procurado evidenciar o papel desempenhado pelo futebol em toda a história do conflito. Assim, a questão que se coloca é a de saber se o futebol, na actualidade, poderá contribuir para uma reaproximação das diferentes populações ou se, pelo contrário, esta é uma arena que não só não favorece como potencia o agravamento das diferenças culturais, religiosas ou políticas.

Sendo o futebol uma prática desportiva que propicia uma oposição binária 'nós/eles' não parece credível que este contexto favoreça uma verdadeira inclusão. Para além disso, uma dimensão muito presente no futebol e que se deve ter em consideração quando se discute as suas possibilidades inclusivas e excludentes, refere-se à importância simbólica que é concedida ao território. Efectivamente, explorando um pouco a própria história do futebol, facilmente se percebe que inúmeras rivalidades entre diferentes equipas relacionam-se com disputas territoriais, seja entre clubes da mesma cidade ou de regiões diferentes. Não é pois, de estranhar, que muitos dos confrontos entre adeptos, nos diferentes países, se registem em contextos em que a disputa simbólica do território se encontra também em jogo. Neste sentido, o hooliganismo nos Balcãs, altamente associado ao nacionalismo extremista e que se tornou uma rotina principalmente nos campeonatos sérvios e croatas, sugere que o futebol não favorece uma reaproximação das diferentes etnias. Com efeito, as tensões étnicas ainda se encontram muito presentes no imaginário das populações e, por conseguinte, dos adeptos. Prova disso, foram os violentos confrontos registados em Belgrado entre os seguidores do Partizan e os adeptos bósnios do NK Mostar em 2007, que levaram, aliás, à suspensão do clube sérvio das competições europeias nessa mesma 
época $^{5} .8$

A hipótese levantada por alguns media acerca da possibilidade de se organizar uma competição internacional que envolvesse os clubes dos países desta zona da Europa, tais como a Sérvia, Croácia, Eslováquia, Eslovénia, Bósnia, Montenegro, Áustria e Hungria mereceu a atenção por parte de alguns dos investigadores. De acordo com Nielsen, ${ }^{1}$ esse campeonato teria consequências desastrosas, já que alguns dos estádios seriam, sobretudo, uma arena de ódio e violência. Com efeito, tendo em atenção uma série de factores que vão desde o grau de violência e destruição ocorridos até ao facto de se terem, apenas, passado vinte anos desde o fim do conflito, a hipótese mais realista vai ao encontro desta perspectiva. Para além de mais, há que ter em consideração que o fenómeno do hooliganismo, ainda que com contornos bem diferentes do resto da Europa, tem assumido proporções consideráveis em vários dos campeonatos nacionais dos países que compunham a federação jugoslava. É interessante salientar que alguns daqueles sobre quem recaem suspeitas de crimes de guerra são os mesmos que controlam determinados clubes e que se têm envolvido, recentemente, em vários episódios de intimidação, violência e homicídios no contexto do futebol. ${ }^{1}$

Na verdade, tem sido sugerido que o futebol nos Balcãs pode abrir novas possibilidades de diálogo e de comunicação entre diferentes grupos étnicos. ${ }^{2-3}$ Segundo esta leitura, alguns

\footnotetext{
${ }^{5}$ São vários os factos que comprovam o clima de tensão que ainda se vive na região. Refira-se, por exemplo, que os jogos que irão opor a Sérvia e a Croácia a contar para a qualificação do Campeonato Mundial de Futebol de 2014, poderão ser efectuados em território 'neutro'. Uma das possibilidades, colocadas pelas entidades reguladoras, nomeadamente pela FIFA, como palco dos jogos é o Chipre (ultraummododevida.blogspot.com). De registar também os confrontos ocorridos entre eslovenos e sérvios, aquando do jogo que opôs as duas selecções para a qualificação do Campeonato da Europa de Futebol de 2000. Mais recentemente, em 2005, o jogo entre as selecções da Bósnia e da Sérvia também ficou marcado por tumultos. Apesar da ausência de adeptos sérvios, por imposição das autoridades políticas e desportivas, o jogo foi interrompido depois dos seguidores bósnios terem arremessado para o relvado várias dezenas de 'tochas'. O comportamento dos adeptos bósnios terá sido a reacção face aos confrontos violentos que tinham ocorrido em Belgrado e que originaram várias dezenas de feridos, alguns em estado grave (http://www.jn.pt/PaginaInicial/Interior.aspx?content_id=520733). Já em 2012 o jogo de qualificação para a fase de grupos da Champions League que colocou frente a frente os eslovenos do NK.Maribor e os croatas do Dínamo de Zagreb foi marcado por pequenos incidentes, tais como o arremesso de objectos pirotécnicos entre as duas torcidas organizadas. No entanto, a presença massiva das forças policiais, que destacaram cerca de mil e quinhentos efectivos para o jogo da 'segunda mão' na Eslovénia, terá evitado confrontos de maior dimensão.
} 
dos obstáculos que se colocam com vista à aproximação de diferentes comunidades prendem-se sobretudo com a ausência de espaços rituais que desempenhariam a função de integrar os vários grupos étnicos. Porém, nem sempre o futebol reforçou os antagonismos entre grupos com identidades distintas. Neste sentido, abordando o futebol como uma forma específica de ritual, sublinha-se a sua potencialidade em contribuir, por exemplo, para a pacificação e integração no sistema social bósnio:

Enquanto os rituais das várias religiões constituem a base para uma interacção distinta e separada, os rituais do futebol partilham uma base fenomenológica transnacional, trans-étnica e trans-religiosa que o torna formalmente semelhante em todo o mundo. ${ }^{3: 217}$

Esta base partilhada dos rituais do futebol tem permitido a construção de projectos humanitários, reavivando as relações entre diferentes etnias e promovendo uma atmosfera de excitação e efervescência colectiva. Enfatizam-se, assim, as características do futebol, enquanto forma de celebração ritual, no qual os membros de uma comunidade específica possam partilhar os significados das suas acções, adaptando os ritmos individuais em prol do colectivo e aumentando os níveis de envolvimento emocional para com o grupo. ${ }^{3}$ Privilegiando uma abordagem intervencionista, realça-se a necessidade de apoiar as estruturas locais para que estas possam ser capazes de promover a paz, estabilidade, democracia e direitos humanos. Deste modo, procuram-se criar espaços comuns, envolvendo jogadores, treinadores e outros actores que, apesar de viverem no mesmo território, não partilhem qualquer tipo de actividades diárias. ${ }^{2}$ É esse o propósito das chamadas 'Open Fun Football Schools', criadas por várias organizações nãogovernamentais em diversos contextos pós-conflito, que envolvem a participação de largas centenas de crianças e adolescentes. Assim, contrariando aquilo que muitas vezes acontece nas competições profissionais de futebol, procura-se, nestes espaços promover uma aproximação e reconciliação entre diferentes grupos étnicos.

Apesar dos estudos da área ainda serem escassos, nos últimos anos têm surgido alguns trabalhos $^{23-26}$ que procuram avaliar, precisamente, o papel do desporto em geral e do futebol em particular, na reunificação entre populações que experienciaram ou experienciam cenários de conflito armado. No caso do Chipre, por exemplo, têm-se verificado algumas tentativas de utilização do futebol enquanto elemento potencialmente unificador entre os cipriotas gregos e cipriotas turcos. Desta forma, através dos esforços de várias instituições, nomeadamente das federações de futebol das duas comunidades, Conexões: revista da Faculdade de Educação Física da UNICAMP, Campinas, v. 10, n. 3, p. 1-19, set./dez. 2012.13 ISSN: 1983-9030 
realizaram-se alguns jogos e torneios de carácter amigável. ${ }^{25}$ No entanto, apesar das várias iniciativas desenvolvidas ao longo dos últimos anos, o sucesso tem sido relativo. De acordo com Kartakouillis e Loizou, ${ }^{25}$ o problema não reside necessariamente na falta de vontade ou de empenhamento das várias instituições desportivas na aproximação das duas comunidades, mas sim nos obstáculos criados pelos poderes políticos que têm impedido a reunificação entre cipriotas gregos e cipriotas turcos.

O papel que o desporto pode ter como instrumento unificador entre a Coreia do Sul e a Coreia do Norte também tem merecido alguma atenção, salientando-se a sua capacidade cooperativa, constituindo-se num importante instrumento diplomático. De facto, sensivelmente a partir da década de 1990, os dois países têm vindo a reforçar as relações a nível desportivo, nomeadamente nos Jogos Olímpicos de 2000, 2004 e 2008 e no Campeonato Mundial de Futebol de 2002. Assim, as entidades políticas dos dois países têm utilizado o desporto como um instrumento para promover e intensificar o diálogo, colocando a "ênfase na celebração das parecenças e da cooperação". ${ }^{24: 424}$ É importante, contudo, destacar dois aspectos importantes em relação à potencialidade de utilização do futebol como instrumento de paz. Em primeiro lugar, muitas das iniciativas que se têm realizado na Coreia do Sul e do Norte dizem respeito a outras práticas desportivas que não o futebol, como por exemplo os Jogos Olímpicos. Com efeito, a especificidade deste tipo de eventos, ainda que numa era de alta comercialização e mediatização das competições desportivas, ainda consegue manter um certo 'espírito olímpico', se o entendermos como a celebração da 'competição saudável' e do 'fair-play'. Para além disso, apesar do futebol ser um desporto popular nas duas Coreias, a sua importância e centralidade não se compara com o que acontece em muitos países europeus e sul-americanos.

Partindo da ideia de que o futebol pode ser uma ferramenta poderosa de reconciliação e reunificação, Howarth ${ }^{26}$ salienta que o futebol não está necessariamente ligado à violência e que o hooliganismo é um "fenómeno periférico" ao próprio jogo, acrescentando ainda que "assistir ou jogar futebol não torna ninguém violento". ${ }^{26: 26}$ Este tipo de leitura parece algo redutora e simplificadora dos complexos aspectos e dimensões que envolvem o futebol e as suas diferentes manifestações. Tal como tem sido salientado, ${ }^{12,}{ }^{27}$ para compreender o fenómeno da violência no futebol é necessário ter em consideração um vasto número de aspectos, que vão desde o significado do próprio jogo e da importância Conexões: revista da Faculdade de Educação Física da UNICAMP, Campinas, v. 10, n. 3, p. 1-19, set./dez. 2012.14 ISSN: 1983-9030 
que as pessoas lhe atribuem, até aos processos de construção das identidades produzidas quer em torno dos clubes e selecções quer dos grupos organizados de apoio. Assim, só tendo presente estas noções é que se poderá ter uma compreensão mais aprofundada das questões de identidade, rivalidade, oposição e violência que têm acompanhado a própria história do futebol profissional.

O problema o tipo de abordagem desenvolvida a partir de projectos como as 'Open Fun Football Schools' ou outras iniciativas de carácter institucional reside na demasiada ênfase concedida a questões como a ordem, coesão social e partilha de valores, que se tornam ainda mais problemáticas quando aplicadas a um contexto como o futebol, no sentido em que este propicia uma terreno fértil para a oposição e conflito. Além disso, tal como foi salientado a propósito da guerra da Coreia, ${ }^{24}$ o facto do conflito dos Balcãs também ter tirado a vida a dezenas de milhares de soldados e civis reforça a ideia de que uma total inclusão entre diferentes comunidades ainda se afigura difícil e distante. Evidentemente, não se pretende negar a possibilidade de se construírem formas de diálogo e de aproximação nos diferentes espaços da vida social.

Os limites desta abordagem, que salienta a potencialidade do futebol em servir estes propósitos, residem no facto de se tratar de escolas de futebol não profissional e destinadas, principalmente, a crianças e jovens. De facto, neste contexto, as formas de inclusão passam, sobretudo, pela formação desportiva ao nível dos jovens e das comunidades nas quais eles se integram. Assim, denota-se uma ausência da carga simbólica associada às competições profissionais, e por conseguinte, as premissas que normalmente estão subjacentes ao próprio jogo alteram-se profundamente. Desta forma, torna-se problemático avaliar o papel do futebol como factor de exclusão ou de integração, já que os campos de análise são amplamente diferenciados.

\section{CONSIDERAÇÕES FINAIS}

Tal como se procurou demonstrar neste artigo, a dimensão política, cultural e simbólica do futebol esteve muito presente no conflito dos Balcãs. Independentemente das origens do desmembramento da Jugoslávia, ficou patente o papel activo que o futebol desempenhou na intensificação e aglutinação de sentimentos nacionalistas e xenófobos. Mais do que isso, o futebol foi um dos principais actores em todo o processo, embora a sua centralidade

Conexões: revista da Faculdade de Educação Física da UNICAMP, Campinas, v. 10, n. 3, p. 1-19, set./dez. 2012.15 ISSN: 1983-9030 
e importância não seja a mesma em todas as federações que compunham o país. Os exemplos citados ao longo do texto comprovam-no.

Quando se analisa o futebol como via de acesso ao estudo da própria sociedade, torna-se evidente que o seu papel activo não se restringiu a uma dimensão simbólica. Tendo servido também como campo de recrutamento para combater na guerra, especialmente entre os grupos organizados de adeptos, pode afirmar-se que o hooliganismo nos Balcãs apresenta contornos bem diferentes daquilo que se verifica na Europa ou na América Latina, nomeadamente no que se refere ao grau de violência e relações com o crime organizado. Neste sentido, pode-se argumentar que a violência no futebol, aliado ao facto de ter sido encorajada e incentivada pelas autoridades, é endémica em alguns dos países que nasceram na sequência do desmembramento do país, especialmente nos casos da Sérvia e Croácia.

Evidentemente, dada a sua natureza heterogénea, o futebol, em determinados contextos, também pode servir como factor de inclusão. No entanto, tal como atrás referido, é importante salientar que essa potencialidade tem as suas limitações. O futebol profissional, pela sua natureza, dificilmente aproxima as pessoas. Efectivamente, as suas especificidades fazem do jogo mais um campo de oposição e rivalidade do que aproximação e união. E, na verdade, serão precisamente algumas dessas características que têm atraído tantos adeptos e que reforçam o papel do futebol como uma instituição cultural central na representação das culturas populares.

Desta forma, a agenda de investigação futura no campo dos estudos sobre futebol e contextos pós-conflito poderá ter que passar por uma análise mais aprofundada sobre as raízes e motivações dos discursos nacionalistas e xenófobos que possam promover uma discussão mais alargada na sociedade sobre a natureza destes fenómenos. Apesar do futebol ter a capacidade de criar ou consolidar determinados valores e normas sociais, para que haja uma verdadeira mudança de atitudes e mentalidades, não se poderá esperar que o desporto em geral e o futebol em particular possam, só por si, provocar transformações sociais tão profundas. 


\section{REFERÊNCIAS}

${ }^{1}$ NIELSEN, C. The goalposts of transition: football as a metaphor for Serbia's long journey to the rule of law. Nationalities Papers: the journal of nationalism and ethnicity, v. 38, n. 1, p. 87-103, 2010.

${ }^{2}$ LEVINSEN, A. Inter-ethnic football in the balkans: reconciliation and diversity. Sport, Ethics and Philosophy, v. 3, n. 3, p. 346-359, 2009.

${ }^{3}$ STERCHELE, D. The limits of inter-religious dialogue and the form of football rituals: the case of Bosnia-Herzegovina. Social Compass, v. 54, n. 2, p. 211-224, 2007.

${ }^{4}$ PODALIRI, C.; BALESTRI, C. The ultras, racism and football in Italy. In: BROWN, A. (Ed.). Fanatics! power, identity and fandom in football. London: Routledge, 1998. p. 88100.

${ }^{5}$ SPAAIJ, R.; VIÑAS, C. Passion, politics and violence: a socio-historical analysis of spanish ultras. Soccer \& Society, v. 6, n. 1, p. 79-96, 2005.

${ }^{6}$ CHAUDHARY, V. Black, brown, blue and white army. In: PERRYMAN, M. (Ed.). Hooligan wars: causes and effects of football violence. Edinburg: Mainstream, 2002. p. $77-83$.

${ }^{7}$ TESTA, A.; ARMSTRONG, G. Football fascism and fandom: the ultras of italian football. London: A\&C Black, 2010.

${ }^{8}$ MARIVOET, S. Violent disturbances in portuguese football. In: DUNNING, E. (Ed.). Fighting fans as a world phenomenon. Dublin: University College, 2002. p. 158-173.

${ }^{9}$ SUGDEN, J. We are leeds!. In: PERRYMAN, M. (Ed.). Hooligan wars: causes and effects of football violence. Edinburg: Mainstream, 2002. p. 95-107.

${ }^{10}$ LOWLES, N. Far out with the far right. In: PERRYMAN, M. (Ed.). Hooligan wars: causes and effects of football violence. Edinburg: Mainstream, 2002. p. 108-121.

Conexões: revista da Faculdade de Educação Física da UNICAMP, Campinas, v. 10, n. 3, p. 1-19, set./dez. 2012. ISSN: 1983-9030 
${ }^{11}$ ROVERSI, A.; BALESTRI, C. Italian ultras today: change or decline?. In: DUNNING, E. (Ed.). Fighting fans as a world phenomenon. Dublin: University of College, 2002. p. 131-142.

${ }^{12}$ ALMEIDA, P. Violência e Euro 2004: a centralidade do futebol na cultura popular. Lisboa: Colibri, 2006

${ }^{13}$ MARIVOET, S. Subculturas de adeptos de futebol e hostilidades violentas: o caso português no contexto europeu. Configurações, v. 5, n. 6, p. 279-289, 2009.

${ }^{14}$ QUIJANO, A. Coloniality of power, eurocentrism and Latin America. Nepantla: views from south, v. 1, n. 3, p. 533-580, 2010.

${ }^{15}$ HESSE, B. Im/plausible deniability: racism's conceptual double bind. Social Identities, v. 10, n. 1, p. 9-29, 2004.

${ }^{16}$ MCCLANCY, J. Nationalism at play: the Basque of Vizcaya and athletic Bilbao. In: . (Ed.). Sport, Identity and Ethnicity, Oxford: Berg, 1996, p. 167-199.

${ }^{17}$ DUKE, V.; CROLLEY, L. Football, nationality and the state. Edinburgh: Longman, 1996.

${ }^{18}$ MILLS, R. It all ended in an unsporting way: Serbian Football and the disintegration of Yugoslavia, 1989-2006. The International Journal of the History of Sport, v. 26, n. 9, p. 1187-1217, 2009.

${ }^{19}$ FOER, F. How football explains the world. London: Arrow Books, 2005.

${ }^{20}$ SACK, A.; SUSTER, Z. Soccer and croatian nationalism: a prelude to war. Sport and Social Issues, v. 24, n. 3, p. 305-320, 2000. 
${ }^{21}$ COHEN, L. Broken bonds: yugoslavia's disintegration and balkan politics in transition. Bolder: Westview, 1995.

${ }^{22}$ RONEN, D. The challenge of ethnic conflict, democracy and self-determination in central europe. London: Frank Cass, 1997.

${ }^{23}$ MERKEL, U. The politics of sport diplomacy and reunification in divided Korea: one nation, two countries and three flags. International Review for the Sociology of Sport, v. 43, n. 3, p. 289-311, 2008.

${ }^{24}$ MERKEL, U. Sport, politics and reunification: a comparative analysis of Korea and Germany. International Journal of the History of Sport, v. 26, n. 3, p. 406-428, 2009.

${ }^{25}$ KARTAKOULLIS, N.; LOIZOU, C. Is sport (football) a unifying force or a vehicle to further separation? the case of cyprus. International Journal of the History of Sport, v. 26, n. 11, p. 1652-1667, 2009.

${ }^{26} \mathrm{HOWARTH}$, J. Is football an appropriate tool to utilize in conflict resolution, reconciliation or reconstruction? contemporary war and peace studies. 2006. Dissertation (MA) - University of Sussex, Sussex, 2006.

${ }^{27}$ ARMSTRONG, G.; GIULIANOTTI, R Fear and loathing in world football. New York: Berg, 2001. 